\title{
Cycle for Science
}

\author{
www.cycleforscience.org
}

www.youtube.com/watch?v=Ed4txeUSIks

\section{Gail Oare}

\begin{abstract}
$\mathrm{A}^{\mathrm{n}}$
mericans headed West in the 1800 s

in covered wagons for better lives and fortunes. Then in the 1900s, many crossed the country in search of personal adventures of the type mythologized in the 1960s television show Route 66 and in Jack Kerouac's On the Road. Today, trekkers are frequently motivated to cross the continent for the higher purpose of generating support for global social causes, such as medical research. Two young scientists from California recently became members of this elite latter category. Also bicycling enthusiasts, Elizabeth Case and Rachel WoodsRobinson literally put a new spin on social outreach by pedaling the width of the country while engaging hundreds of students along the way in enjoyment of science and appreciation of its potential to solve real-world problems.

Their 3500-mile bike trip began in April 2015 and ended in mid-July in
\end{abstract}

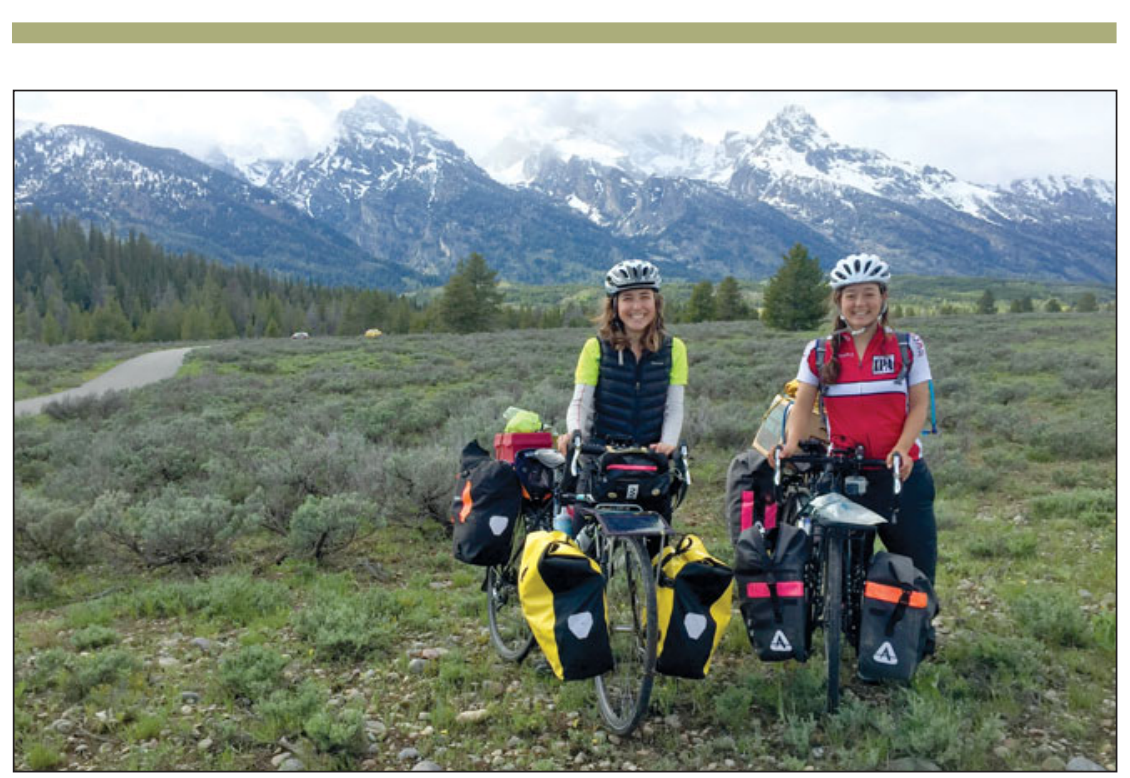

Rachel Woods-Robinson (left) and Elizabeth Case pause at the Grand Tetons at the beginning of month two of their trip. From here they camped at Jenny Lake, rode over Twogotee Pass (and

the Great Divide) and on to Casper, Wyo., where they taught a middle-school class.
New York City after 89 days on the road. Prior to their departure, they had developed the title of "Cycle for Science" and adopted the theme of renewable energy to illustrate their message. They visits along their path, and designed a solar-driven model bicycle for use in the classroom. Using a three-dimensional (3D) printer, they produced copies of this Sol Cycle that they carried with them for use in the 22 workshops they would conduct at 10 locations in California, Idaho, Wyoming, Iowa, Indiana, Pennsylvania, and New York.

"We planned our workshop for middle-school students," Case said, "but we actually worked with students from ages 4 through 18." Undaunted, they adjusted their lessons as needed to accommodate everyone in the classes.

Their "Cycle for Science" lesson plan started with introductions and a then solicited support, scheduled school description of exciting careers in science. Woods-Robinson is a materials researcher and Case is pursuing her $\mathrm{PhD}$ degree in mechanical engineering. Next they introduced the concept of 3D printing and its advantages over other manufacturing methods, followed by a brief physics lesson on photovoltaic energy conversion and a discussion of atoms. With older students, they also discussed photons and the concept of particle/wave duality. Then the workshop fun really began.

In a short skit about energy, four students played the roles of the sun, a nucleus of a silicon atom, a low-energy electron orbiting the nucleus, and a motor. In the performance, the sun threw off packets of quantized energy ("role-played" by candy or snack bars). The newly energized electron then broke free of its nucleus until the hungry motor grabbed the energy packets. As the motor began to spin, the sad electron returned to its low-energy state around the nucleus to await the arrival of the next photon.

After role-playing, the students were ready to construct and operate their Sol Cycle. Teams worked to figure out how to attach the motor, where to put the rubber bands to achieve the most efficient gear ratio, and how to connect the alligator clips from the solar panel to the terminals of the motor. "We took them outside, where the kids were able to conduct their own experiments on the Sol Cycles," explained Woods-Robinson. "When a clip came off or short-circuited, or when the training wheels shifted causing the bike to wobble, the students had to assess the problem and fix it themselves."

"Usually" she added, "it would lead to a wild Sol Cycle race."

Each class was then given at least one Sol Cycle so they could continue their work long after the bicycling scientists disappeared over the horizon. 
The workshop was a special experience for the students and they were positive about the things they learned. Many were excited about the concept of 3D printing. Some students who have access to a $3 \mathrm{D}$ printer even planned to work on an improved Sol Cycle 2.0. "One of my favorite moments was in Waterloo, Iowa," Woods-Robinson said. "A little girl got so excited about what she could build with a $3 \mathrm{D}$ printer that she asked if she could produce "even a flying pig?"”

The students also came to realize that anyone could be a scientist if they were inquisitive and willing to look at problems such as renewable energy from another perspective. The two scientists acknowledged that they were not intending to convince all the students to become scientists. They did hope, however, that the students would see that science literacy was important for other professions as well, such as lawmakers and economists who are involved in solving major social challenges.

"We taught a group of Burmese refugee students in Philadelphia who didn't know what a 3D printer was. We also had an incredible language barrier with them," Case said. "But by the end of the workshop, it really didn't matter."

Woods-Robinson agreed. "At the end of the lesson," she said, "an eleventh grader who had initially boasted 'I hate science' told us that she was now interested in studying the role of international relations in renewable energy and science."

The hosting teachers likewise were enthusiastic about the experience. Brian Whitney, STEM (science, technology, engineering, and math) specialist at Hidden Springs Elementary in Boise, Idaho, arranged for 60 students to participate in the workshop. "Rachel and Elizabeth covered some basic energy content, infused with a decent dose of higher level questioning and some engaging higher level content as well! They did a great job of compacting a potentially complex topic into a manageable 15-minute lesson prior to the hands-on activities," Whitney said.

"The construction of the solar cycle was a great activity," noted Polly Beebout, science teacher at CY Middle School in
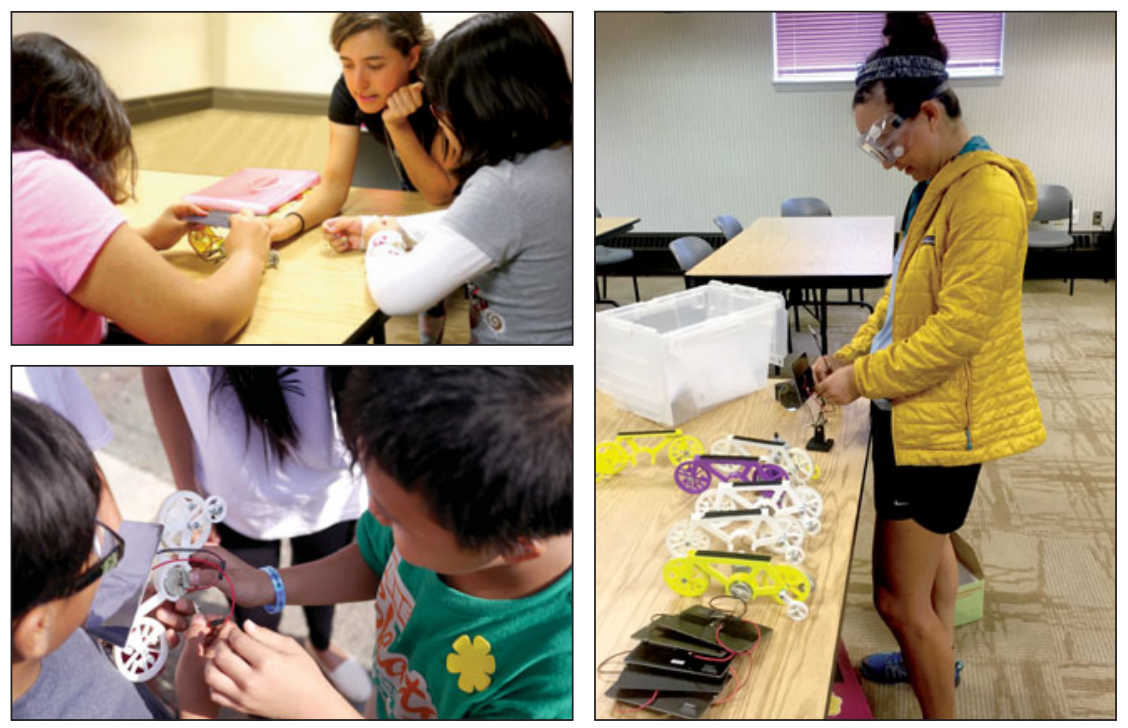

From top left clockwise: Rachel Woods-Robinson helps two participants piece together a Sol Cycle at a library in Indiana. Elizabeth Case prepares the Sol Cycles. Two children work together to re-attach the motor to the solar panel in Pennsylvania.

Casper, Wyo., where Case and WoodsRobinson conducted five workshops and three Career Day sessions. "The students will remember how a solar panel works and the importance of conservation," she said. "It was real-life learning about reallife issues facing our kids."

Other benefits resulted from simply being face to face with the scientists, Whitney said. "Students learned that Rachel and Elizabeth were excited about their work and were fun people. And the fact that they are both female added a silver lining. They are great role models."

For the bicycling scientists, "Cycle for Science" was a fun and satisfying classroom experience as well as an adventure of a lifetime. Prior to the trip, neither of them had undertaken bike trips much longer than 35 miles. "I had no idea what 3500 miles meant," Woods-Robinson said. "I doubted myself."

Case agreed. "It was challenging both physically and mentally."

But the two quickly realized that concentrating on small goals along the way was their key to success. They narrowed their focus to one day and sometimes one mile at a time. They directed their attention to the daily decisions of contending with the thunderstorms they were tracking, achieving their mileage quota, and determining what they would eat that day and where they would sleep that night. The success of their trip was the sum of these daily achievements.

"Our strategy was not unlike how scientific challenges will need to be tackled in the future," Woods-Robinson said. "It's going to take a series of small, creative advances from curious people like these students to make big changes in our energy infrastructure and in emerging technologies."

"On a personal level, I also found that I faced every day of the trip with joy and gratitude," Case said. "There was rain, hot sun, and road kill, but there were also unbelievable scenery and rainbows. I now want to go backpacking!”

But until then, they will resume their regular lives. Woods-Robinson returns to her work at Lawrence Berkeley National Laboratory and Case to Cornell University to pursue her $\mathrm{PhD}$ degree.

They will also enjoy some downtime to reflect on the many great memories of their cross-country adventure. When they look back with satisfaction at the many students they inspired, they will likely remember the fifth grade girl in Boise who told them, "I want to do what you do when I grow up. I want to bike across the country and be a scientist!" 


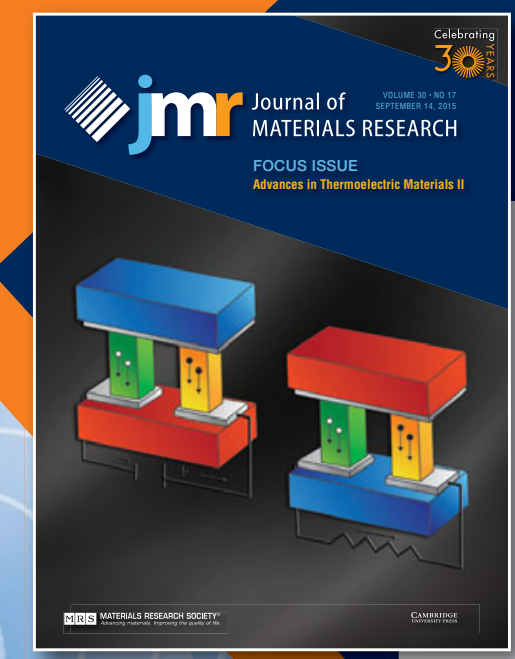

\section{PROPOSALS are now being accepted}

for JMR Focus Issues to be published in 2017.

\section{SUBMISSION DEADLINE-DECEMBER 1, 2015}

Although each regular issue of JMR covers a range of materials research topics, Focus Issues are devoted entirely to a single topic and are published several times a year. Focus Issues allow the journal to comprehensively examine the current research in a particular area of interest to JMR readers. See www.mrs.org/jmr-focus for previously published and planned Focus Issues.

\section{Lead a Focus Issue on your area of expertise!}

Proposals should provide:

\section{- PROPOSED TOPIC}

Topics should be interdisciplinary materials research and focused on the science of the field. Focus Issues should cover emerging and progressing fields in materials or topics that would benefit from comprehensive coverage.

\section{- PROPOSED GUEST EDITOR NAMES AND FULL CONTACT INFORMATION}

Three to four guest editors, representing the diversity of the Materials Research Society ${ }^{\circledR}$, are required. Guest editors should be knowledgeable in the field of the proposed topic, able to present a balanced view of the topic, organized, and able to meet deadlines. Previous editorial experience is a plus.

\section{- OVERALL SCOPE}

Describe the Focus Issue topic in one or two paragraphs, and why a Focus Issue is important at this time. Evaluation will be based on scientific value, presentation quality and plans to attract cutting-edge papers in the field.

\section{- PROPOSED SCHEDULE TO PRODUCE THE ISSUE}

During what quarter of 2016 (January-March / April-June / July-September / October-December) do you prefer to organize the Focus Issue? For 2017 publication, the Call for Papers should be released by JMR at least 12 months before the publication date.

Visit www.mrs.org/jmr-proposals-2017 for more information and guidelines regarding required elements. Submit your proposal to the JMR Editor-in-Chief at jmr@mrs.org no later than December 1, 2015.

Focus Issue topics for 2017 will be selected by the Editor-in-Chief and Associate Editors by January 30, 2016.

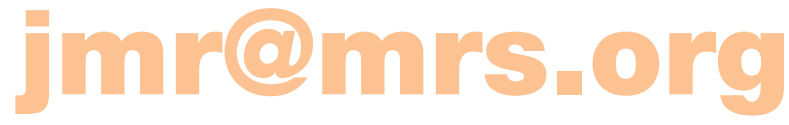

Please contact jmr@mrs.org with questions. 